\title{
Estimasi Nilai Heritabilitas Lingkar Dada dan Panjang Badan pada Kambing Peranakan Etawah di BPTU dan HPT Pelaihari Kalimantan Selatan
}

\section{Estimation of Heritability Value and Breeding Value of Body Length and Chest Girth in Etawah Grade at BPTU and HPT Pelaihari South Kalimantan}

M. F. Amin, G. Ciptadi*, \& V. M. A. Nurgiartiningsih

Departemen Ilmu Produksi dan Teknologi Peternakan, Fakultas Peternakan, Universitas Brawijaya

J1. Veteran, Malang 65145, Indonesia

*Corresponding author: ciptadi@ub.ac.id

(Received 16-07-2021; Revised 05-09-2021; Accepted 20-09-2021)

\begin{abstract}
Evaluation in standardization really needs to be carried out, including whether the livestock is in accordance with the SNI vital statistics standard (Indonesian national standard). The purpose of the study was to estimate heritability and breeding values of body weight and vital statistics in Etawah Grade (PE) goats in BPTU and HPT Pelaihari Kalimantan Selatan. The material used were the performance records of $220 \mathrm{PE}$ goats, offsprings of 35 males and 71 females. The variables measured were body length and chest girth at birth, weaning, and 1 year of age. Variance componenet were analyzed using variance analysisrade. Heritability was estimated using the paternal half-sib correlation method by applying SPSS software. Breeding value was estimated using the progeny test model. The highest breeding value on body length at birth, at weaning age and at 1 year of age were sire $3315 \mathrm{KK}$, sire $4093 \mathrm{OK}$, and sire $4007 \mathrm{OK}$, respectively. The highest breeding Value on chest girth at birth, weaning age and 1 year of age were sire $3983 \mathrm{HH}, 3315 \mathrm{HH}$, and $3971 \mathrm{HH}$. The conclusion of this study were the heritability for body weight were categorized high and for statistic vital were varied from medium to high value.
\end{abstract}

Keywords: Heritability, Breeding Values, Body length, Chest Girth, Etawah Grade

\section{ABSTRAK}

Evaluasi dalam standarisasi sangat perlu dilaksanakan, termasuk apakah ternak tersebut sudah sesuai dengan standart ukuran statistik vital SNI (standart nasional Indonesia). Tujuan penelitian adalah untuk mengestimasi nilai heritabilitas dan nilai pemuliaan bobot badan dan statistik vital kambing Peranakan Etawah (PE) di BPTU dan HPT Pelaihari Kalimantan Selatan. Materi dalam penelitian ini adalah data catatan performan dari 220 ekor kambing PE keturunan dari 35 ekor pejantan dan 71 ekor betina. Variabel yang dianalisis adalah panjang badan (PB) dan lingkar dada (LD) pada umur lahir, sapih dan 1 tahun. Komponen ragam diestimasi dengan analisis ragam. Nilai heritabilitas diestimasi menggunakan metode korelasi saudara tiri sebapak dengan mengaplikasikan software SPSS. Nilai pemuliaan dihitung dengan model uji keturunan. Hasil penelitian menunjukkan nilai heritabilitas bobot badan dan statistik vital kambing PE umur lahir berkisar 0.36-0.89 ; umur sapih adalah 0.54-0.98; dan umur 1 tahun adalah 0.33-0.73. Nilai pemuliaan tertinggi Nilai Pemuliaan tertinggi panjang badan untuk umur lahir adalah pejantan $3315 \mathrm{KK}$, untuk umur sapih adalah pejantan 4093 OK, untuk umur 1 tahun adalah pejantan 4007 OK. Nilai Pemuliaan tertinggi Lingkar dada untuk umur lahir adalah pejantan 3983 KK, umur sapih adalah pejantan $3315 \mathrm{KK}$, umur 1 tahun tertinggi adalah pejantan $3971 \mathrm{KK}$. Kesimpulan dari penelitian ini adalah nilai heritabilitas statistik vital bervariasi dari medium hingga tinggi. Nilai pemuliaan positip untuk semua varaiabel yang diamati hanya dimiliki oleh pejantan 4007 OK dan 3205 KK.

Kata kunci: Heritabilitas, Nilai Pemuliaan, Panjang Badan, Lingkar Dada, Peranakan Etawah 


\section{PENDAHULUAN}

Peningkatan produktivitas ternak kambing dapat dilakukan melalui persilangan dan seleksi pada sifat-sifat yang memiliki nilai ekonomis tinggi seperti bobot sapih, bobot satu tahun dan pertumbuhan setelah sapih. Program pemuliabiakan ternak kambing dapat dilakukan melalui seleksi atau pengaturan perkawinan. Seleksi merupakan program pemuliabiakan yang efektif apabila parameter genetik (heritabilitas, nilai pemuliaan) suatu sifat berkisar antara sedang sampai tinggi Fallis (2003). Dalam program pemuliaan ternak, sifat kuantitatif merupakan variabel penting karena mempunyai nilai ekonomis tinggi. Sifat kuantitatif pada kambing adalah bobot pada waktu lahir dan bobot waktu sapih Kurnianto et al. (2012).

Pengembangan produktivitas kembing Peranakan Etawah (PE) terus dilakukan melalui proses seleksi dan persilangan. Kambing PE merupakan proses upgrading kambing kacang dengan kambing Etawah, Salah satu upaya pemerintah untuk mempertahankan dan meningkatkan mutu genetik kambing PE adalah melalui penetapan rumpun kambing Peranakan Etawah sebagai kekayaan sumber daya genetik ternak lokal Indonesia yang dituangkan dalam Keputusan Menteri Pertanian pada Nomor : 695/Kpts/PD.410/2/2013. Pemerintah terus melakukan pengembangan produktivitas dan mutu genetik dari kambing Peranakan Etawah yang ada di Indonesia dengan memberikan kewenangan kepada Balai Pembibitan Ternak Unggul dan Hijauan Pakan Ternak (BPTU dan HPT) Pelaihari di Kalimantan Selatan untuk melakukan pembibitan ternak unggul kambing PE.

Kambing PE memiliki keunggulan dalam beradaptasi, daya produksi, dan reproduksi yang tinggi. Berbagai keunggulan yang dimiliki, antara lain mempunyai harga jual yang mahal sehingga banyak dipelihara masyarakat sebagai hewan ternak. Kambing PE memiliki ciri khas yang tidak dimiliki oleh kambing dari galur lainnya dan merupakan sumber daya genetik lokal Indonesia yang perlu dijaga dan dipelihara kelestariannya Edy dan Johari (2015).

Peningkatan performan dan mutu genetik kambing PE dilakukan melalui program pemuliaan melalui seleksi yang didasarkan pada parameter genetik (heritabilitas dan nilai pemuliaan). Oleh karena itu perlu dilakukan penelitian untuk mengestimasi nilai parameter genetik sifat-sifat pertumbuhan kambing PE di wilayah tersebut.

\section{MATERI DAN METODE}

Penelitian dilaksanakan di Balai Pembibitan ternak Unggul dengan data rentang 2014-2018. Materi yang digunakan dalam penelitian ini adalah data rekording dari 220 ekor kambing PE yang berumur satu hari, sapih dan satu keturunan dari 35 ekor pejantan dan 71 ekor induk yang dipelihara pada tahun 2014-2018 di BPTU dan HPT Pelaihari Kalimantan Selatan. Metode penelitian yang digunakan adalah studi kasus. Penentuan sampel dilaksanakan dengan cara purposive sampling. Variabel yang diamati antara lain lingkar dada lahir, lingkar dada sapih, lingkar dada satu tahun. Estimasi nilai heritabilitas dianalisa dengan metode korelasi saudara tiri sebapak (paternal halfsib correlation) komponen ragam dihitung menggunakan analisis ragam Rancangan Acak Lengkap searah.

Pada penelitian ini, perhitungan heritabilitas menggunakan metode korelasi saudara tiri (paternal halfsib correlation). Pemisahan komponen ragam genetik dan lingkungan dilakukan menggunakan analisis variansi satu arah (completely randomized design one way classification) dengan rumus statistik menurut Becker (1992) sebagai berikut :

$$
\text { Yik }=\mu+\alpha i+e i k
$$

Keterangan:

Yik= performa individu ke-k pada pengukuran ke-i

$\mu \quad=$ mean

ai $\quad=$ pengaruh individu ke-i

eik = simpangan lingkungan dan genetik dari pengukuran di dalam suatu individu.

sebagai berikut:

Tabel 1. Sumber Keragaman Rancangan Acak Lengkap

\begin{tabular}{lcccc}
\hline Sumber Keragaman & $\mathrm{db}$ & $\mathrm{JK}$ & $\mathrm{KT}$ & $\mathrm{E}(\mathrm{KT})$ \\
\hline Pejantan (sire) & $\mathrm{s}-1$ & $\mathrm{JKs}$ & $\mathrm{KTs}$ & $\sigma_{w}^{2}+k \sigma_{s}^{2}$ \\
$\begin{array}{l}\text { Keturunan dalam pejantan } \\
\text { progeny-sire) }\end{array}$ & $\mathrm{n}-\mathrm{s}$ & $\mathrm{JKw}$ & $\mathrm{KTw}$ & $\sigma_{w}^{2}$ \\
Total & $\mathrm{n}-1$ & $\mathrm{JKt}$ & & \\
\hline
\end{tabular}

Keterangan:

$\mathrm{db} \quad=$ derajat bebas

JK $=$ Jumlah Kuadrat

JKs = Jumlah Kuadrat dalam Pejantan (sum of square sire)

$\mathrm{JKw}=$ Jumlah Kuadrat keturunan dalam pejantan (sum of square progeny-sire)

$\mathrm{n} \quad=$ Jumlah Individu (individual number)

= ragam keturunan dalam pejantan (variance of progeny-sire)

= Ragam pejantan (variance of sire)

$\mathrm{k} \quad=$ Konstanta

Selanjutnya rumus yang digunakan dalam menghitung nilai heritabilitas $\left(\mathrm{h}^{2}\right)$ berdasarkan analisis kemiripan antar saudara tiri dirumuskan sebagai berikut (Nurgiatiningsih 2017) :

$$
h^{2}=4 t \quad \mathrm{t}=\frac{4 \sigma_{s}^{2}}{\sigma_{s}^{2}+\sigma_{w}^{2}}
$$

di mana :

$$
\begin{aligned}
& \sigma_{w}^{2}=\mathrm{KTw} \\
& \sigma_{s}^{2}=\frac{K T s-K T w}{k} \\
& k=\frac{1}{s-1}\left(n-\frac{\sum n^{2}}{n}\right)
\end{aligned}
$$


Akurasi dan ketepatan estimasi nilai heritabilitas diukur dengan nilai galat baku (standart error), nilai standard error dari heritabilitas sesuai dengan Becker (1985) adalah sebagai berikut:

$$
S E\left(h^{2}\right)=4 \sqrt{\frac{2(n-1)(1-t)^{2}[1 \pm(k-1) t]^{2}}{k^{2}(n-1)(s-1)}}
$$

Nilai ragam pejantan dan keturunan antar pejantan yang digunakan untuk melakukan perhitungan heritabilitas diperoleh sebagai berikut. Sehingga diperoleh hasil perhitungan, heritabilitas dan standar eror $\left(\mathrm{h}^{2}\right)$.

Perhitungan Nilai Pemuliaan pada penelitian ini berdasarkan performans saudara. Pada perhitungan metode ini dengan hubungan saudara tiri yang diperoleh dari hasil perkawinan seekor pejantan dengan beberapa induk, dan beberapa induk menghasilkan hanya satu keturunan (Nurgiatiningsih 2017). Perhitungan rumus Nilai pemuliaan dihitung secara relatif dengan rumus sebagai berikut :

$$
N P_{n}=\frac{n h^{2}}{1+(n-1) r}\left(\bar{p}_{j}-\bar{P}\right)
$$

\section{Keterangan:}

$\mathrm{NP}_{\mathrm{n}} \quad=$ nilai Pemuliaan yang dihitung berdasarkan pengamatan berulang.

$\mathrm{nh}^{2} \quad=$ jumlah pengamatan heritabilitas

$\mathrm{n} \quad=$ jumlah pengamatan

$\mathrm{r} \quad=$ angka pengulangan

$\mathrm{P}_{\mathrm{j}} \quad=$ rata-rata Performans Individu

$\mathrm{P}^{\mathrm{j}} \quad=$ rerata performans populasi dimana individu diukur

\section{HASIL DAN PEMBAHASAN}

\section{Nilai Heritabilitas Panjang Badan dan Lingkar Dada}

Hasil penelitian ini menunjukkan bahwa nilai estimasi heritabilitas panjang badan dan lingkar dada pada kambing Peranakan Etawah di Balai Pembibitan Ternak Unggul dan Hijauan Pakan Ternak Pelaihari - Kalimantan Selatan dapat dilihat pada Tabel 2. Nilai heritabilitas statistik vital pada panjang badan dan lingkar dada umur 1 hari, 90 hari dan 365 hari termasuk kategori tinggi kecuali pada lingkar dada lahir dan panjang badan umur satu tahun yang berturut-turut sebesar $0.42 \pm 0.21$ dan $0.38 \pm 0.06$. Menurut Nurgiatiningsih (2017) nilai heritabilitas termasuk kategori rendah jika nilainya lebih kecil dari 0.5 (15\%); kategori sedang jika lebih besar atau sama dengan 0.20-0.50 (20$50 \%$ ); sedangkan kategori tinggi jika lebih besar dari 0.5 $(50 \%)$.

Tabel 2. Nilai heritabilitas panjang badan dan lingkar dada

\begin{tabular}{cccc}
\hline \multirow{2}{*}{$\begin{array}{c}\text { Ukuran } \\
\text { Tubuh }\end{array}$} & \multicolumn{3}{c}{$\mathrm{h}^{2} \pm \mathrm{SE}$} \\
\cline { 2 - 4 } & Lahir & Sapih & Setahun \\
\hline PB $(\mathrm{cm})$ & $0.51 \pm 0.04$ & $0.54 \pm 0.22$ & $0.42 \pm 0.21$ \\
LD $(\mathrm{cm})$ & $0.38 \pm 0.06$ & $0.88 \pm 0.26$ & $0.73 \pm 0.24$ \\
\hline
\end{tabular}

Nilai heritabilitas hasil penelitian lebih tinggi dari Sulastri et al. (2019) yang melaporkan bahwa nilai heritabilitas kambing Peranakan Etawah di Kelompok Tani Margarini pada lingkar dada lahir; $0.21 \pm 0.05$ pada lingkar dada sapih; $0.22 \pm 0.06$ pada lingkar dada satu tahun. Perbedaan hasil taksiran ini disebabkan oleh lokasi penelitian yang berbeda dan waktu pengambilan data yang berbeda. Ragam perbedaan nilai heritabilitas tersebut disebabkan oleh bangsa ternak yang berbeda (Hidayati et al. 2015).

\section{Nilai Pemuliaan (Breeding Value)}

Nilai pemuliaan atau breeding value (BV) merupakan penilaian dari mutu genetik ternak untuk suatu sifat tertentu yang diberikan secara relatif atas dasar kedudukannya di dalam populasi (Hardjosubroto 1994). Nilai Pemuliaan ditentukan oleh pengaruh kombinasi gen-gen aditif di bawah populasi (Maylida 2010). Hasil dari perhitungan estimasi nilai pemuliaan pada ternak kambing peranakan etawah dapat dilihat pada Tabel 3 dan 4 .

Tabel 3. Rangking panjang badan lahir, sapih dan satu tahun kambing PE

\begin{tabular}{ccccccc}
\hline $\begin{array}{c}\text { No. } \\
\text { Ear Tag }\end{array}$ & $\begin{array}{c}\text { Rang- } \\
\text { king }\end{array}$ & $\begin{array}{c}\text { NP } \\
\text { PBL }\end{array}$ & $\begin{array}{c}\text { Rang- } \\
\text { king }\end{array}$ & $\begin{array}{c}\text { NP } \\
\text { PBS }\end{array}$ & $\begin{array}{c}\text { Rang- } \\
\text { king }\end{array}$ & $\begin{array}{c}\text { NP } \\
\text { PB 1 } \\
\text { Tahun }\end{array}$ \\
\hline $3315 \mathrm{KK}$ & 1 & 1.53 & 4 & 2.72 & 19 & -0.23 \\
$4305 \mathrm{OK}$ & 2 & 1.35 & 14 & 0.74 & 16 & -0.01 \\
$3803 \mathrm{KK}$ & 3 & 1.25 & 7 & 1.81 & 26 & -0.97 \\
$3983 \mathrm{KK}$ & 4 & 1.25 & 18 & -0.33 & 34 & -4.39 \\
$4093 \mathrm{OK}$ & 5 & 1.25 & 1 & 3.56 & 3 & 3.56 \\
$4407 \mathrm{OK}$ & 6 & 1.25 & 17 & 0.15 & 14 & 0.67 \\
$3205 \mathrm{KK}$ & 7 & 1.06 & 3 & 2.78 & 5 & 3.27 \\
$4007 \mathrm{OK}$ & 8 & 0.82 & 6 & 1.94 & 1 & 3.61 \\
$4113 \mathrm{OK}$ & 9 & 0.65 & 28 & -1.79 & 21 & -0.66 \\
$0389 \mathrm{KH}$ & 10 & 0.53 & 33 & -3.49 & 27 & -1.02 \\
$3939 \mathrm{KK}$ & 11 & 0.53 & 10 & 0.88 & 22 & -0.78 \\
$4033 \mathrm{OK}$ & 12 & 0.38 & 5 & 2.39 & 6 & 2.88 \\
$4035 \mathrm{OK}$ & 13 & 0.28 & 24 & -0.94 & 9 & 1.75 \\
$3989 \mathrm{KK}$ & 14 & 0.28 & 13 & 0.75 & 29 & -1.53 \\
$4047 \mathrm{OK}$ & 15 & 0.28 & 8 & 1.42 & 8 & 1.82 \\
$4437 \mathrm{OK}$ & 16 & 0.28 & 32 & -2.76 & 28 & -1.26 \\
$3043 \mathrm{KK}$ & 17 & 0.18 & 23 & -0.87 & 30 & -1.74 \\
$3895 \mathrm{KK}$ & 18 & 0.09 & 16 & 0.25 & 7 & 2.11 \\
\hline
\end{tabular}

\section{a. Panjang badan}

Hasil penelitian menunjukkan bahwa rata-rata nilai pemuliaan panjang badan pada kambing peranakan etawah pada Tabel 3. Hasil penelitian menunjukkan bahwa rangking nilai pemuliaan dari 18 ekor tertinggi pada panjang badan negatif sebanyak (15 NP). Rangking nilai pemuliaan yang bersifat positif sebanyak (39 NP). Rangking terbaik adalah panjang badan pada no. ear tag 3315 KK yang mempunyai rangking 1 pada $\mathrm{PB}$ lahir, rangking 2 pada $\mathrm{PB}$ sapih dan rangking 7 pada $\mathrm{PB}$ satu tahun. 
Tabel 4. Rangking lingkar dada lahir, sapih dan satu tahun kambing PE

\begin{tabular}{ccccccc}
\hline $\begin{array}{c}\text { No. } \\
\text { Ear Tag }\end{array}$ & $\begin{array}{c}\text { Rangk- } \\
\text { ing }\end{array}$ & $\begin{array}{c}\text { NP } \\
\text { LDL }\end{array}$ & $\begin{array}{c}\text { Rangk- } \\
\text { ing }\end{array}$ & $\begin{array}{c}\text { NP } \\
\text { LDS }\end{array}$ & $\begin{array}{c}\text { Rangk- } \\
\text { ing }\end{array}$ & $\begin{array}{c}\text { NP LD } \\
\text { 1Tahun }\end{array}$ \\
\hline $3983 \mathrm{KK}$ & 1 & 1.87 & 20 & -0.24 & 11 & 1.28 \\
$3315 \mathrm{KK}$ & 2 & 1.81 & 1 & 3.10 & 5 & 3.13 \\
$4113 \mathrm{OK}$ & 3 & 1.63 & 27 & -1.59 & 32 & -3.32 \\
$4407 \mathrm{OK}$ & 4 & 1.40 & 3 & 2.96 & 27 & -1.91 \\
$3205 \mathrm{KK}$ & 5 & 1.20 & 5 & 2.17 & 10 & 1.43 \\
$3339 \mathrm{KK}$ & 6 & 1.16 & 26 & -1.47 & 34 & -5.34 \\
$4033 \mathrm{OK}$ & 7 & 1.01 & 8 & 1.78 & 22 & -0.73 \\
$4305 \mathrm{OK}$ & 8 & 0.92 & 4 & 2.47 & 31 & -2.59 \\
$3919 \mathrm{KK}$ & 9 & 0.76 & 6 & 2.14 & 9 & 1.69 \\
$3895 \mathrm{KK}$ & 10 & 0.63 & 12 & 1.39 & 4 & 3.78 \\
$4047 \mathrm{OK}$ & 11 & 0.53 & 11 & 1.39 & 30 & -2.40 \\
$3803 \mathrm{KK}$ & 12 & 0.44 & 10 & 1.58 & 17 & -0.53 \\
$3939 \mathrm{KK}$ & 13 & 0.44 & 19 & 0.01 & 7 & 2.75 \\
$4093 \mathrm{OK}$ & 14 & 0.44 & 2 & 2.96 & 33 & -3.38 \\
$4201 \mathrm{OK}$ & 15 & 0.24 & 25 & -1.17 & 26 & -1.61 \\
$3043 \mathrm{KK}$ & 16 & 0.22 & 21 & -0.98 & 29 & -2.34 \\
$4035 \mathrm{OK}$ & 17 & 0.14 & 16 & 0.62 & 19 & -0.56 \\
$4007 \mathrm{OK}$ & 18 & 0.12 & 9 & 1.76 & 12 & 0.92 \\
\hline
\end{tabular}

\section{b. Nilai Pemuliaan Lingkar Dada}

Hasil penelitian menunjukkan bahwa rata-rata nilai pemuliaan lingkar dada pada kambing peranakan etawah pada Tabel 4. Hasil penelitian menunjukkan bahwa rangking nilai pemuliaan dari 18 ekor tertinggi pada lingkar dada negatif sebanyak (16 NP). Rangking nilai pemuliaan yang bersifat positif sebanyak (38 NP). Rangking terbaik adalah panjang badan pada no. ear tag 3983 KK yang mempunyai rangking 1 pada LD lahir, rangking 20 pada LD sapih dan rangking 11 pada LD satu tahun.

\section{KESIMPULAN}

Nilai heritabilitas pada statistik vital panjang badan dan lingkar dada pada kambing Peranakan Etawah bersifat tinggi dan sedang. Heritabilitas yang dikategorikan tinggi adalah panjang badan lahir, panjang badan sapih, lingkar dada sapih dan lingkar dada satu tahun. Nilai heritabilitas tertinggi pada sifat tersebut yaitu pada lingkar dada sapih. Pejantan dengan nilai pemuliaan positif untuk semua sifat yang diamati pada semua kelompok umur adalah pejantan 4007 OK dan 3205 KK.

\section{DAFTAR PUSTAKA}

Becker, W. A. 1985. Manual of quantitative genetics. McNaughton and Gunn. Ann Arbor, MI.

Becker, W. A. 1992. Manual of Quantitative Genetics., Genet. Mol. Biology. 34(2):225-230.

Beyleto, V. Y., Sumadi, \& T. Hartatik. 2010. Estimasi parameter genetik sifat pertumbuhan kambing boerawa di kabupaten tanggamus propinsi lampung. Buletin Peternakan. 34(3):138-144.

Ciptadi, G., A. Budiarto, \& Y. Oktanella. 2019. Genetika dan Pemuliaan: Peternakan-Veteriner. Universitas Brawijaya Press.

Edy, \& S. H. S. K. Johari. 2015. Analisis ragam dan peragam bobot badan kambing peranakan Ettawa. 16(1):107-116.

Fallis, A. 2013) “済無No Title No Title,” Journal of Chemical Information and Modeling. 53(9):16891699. doi: $10.1017 /$ CBO9781107415324.004.

Hamdan, A. et al. 2018. Respon Kinerja Produksi dan Fisologis Kambing Peranakan Ettawa terhadap Pemberian Pakan Tambahan Dedak Halus pada Agroekosistem Lahan Kering di Kalimantan Selatan. Jurnal Pengkajian dan Pengembangan Teknologi Pertanian. 21(1):73. doi: 10.21082/jpptp.v21n1.2018. p73-84.

Hardjosubroto, W. 1994. Aplikasi Pemuliabiakan Ternak Di Lapangan. PT Grasindo. Jakarta.

Hidayati, S., E. Kurnianto, \& S. Johari. 2015. Analisis ragam dan peragam bobot badan kambing peranakan Ettawa. Jurnal Veteriner. 16(1):107-116.

Karnaen. 2008. Pendugaan Heritabilitas Bobot Lahir dan Bobot Sapih Sebagai Dasar Seleksi Kambing Peranakan Etawah. Jurnal Ilmu Ternak. 8(1):52-55.

Kurnianto, E. 2009. Pemuliaan Ternak. Yogyakarta: Graha Ilmu.

Kurnianto, E., S. Johari, \& H. Kurniawan. 2012. Kompnen Ragam Bobot Badan Kambing Peranakan Etawa Di Balai Pembibitan Ternak Kambing Sumberrejo Kabupaten Kendal. J. Indon. Trop. Anim. Agric. 32(4):236-244.

Maylinda, S. 2010. Pengantar Pemuliaan Ternak. Universitas Brawijaya Press. Malang.

Mulyadi, H. 2013. Parameter Genetik Kambing Peranakan Etawah di Balai Pembibitan Ternak Kambing Sumber Rejo Kendal Jawa Tengah. Buletin Peternakan. 14(2):9. doi: 10.21059/buletinpeternak.v14i2.1763.

Noor, R. R. 2010. Genetika Ternak. 6 th. Jakarta: Penebar Swadaya.

Nurgiatiningsih, V. M. A. 2017. Pengantar Parameter Genetik pada Ternak. Malang978: UB Press.

Pratikto, A. 2018. Estimasi Nilai Heritabilitas Berat Badan Kambing Peranakan Etawah di Balai Pembibitan Ternak Unggul - Hijauan Pakan Ternak Pelaihari - Kalimantan Selatan. Universitas Gadjah Mada. Tersedia pada: http:// etd.repository.ugm.ac.id/penelitian/detail/164768.

Sulastri et al. 2012. Estimasi parameter genetik dan kemampuan berproduksi performans pertumbuhan kambing rambon. Jurnal AgriSains. 1-16. 
Sulastri, M. D. I. Hamdani, \& A. Dakhlan. 2019. Dasar Pemuliaan Ternak. AURA, CV. Anugrah Utama Raharja.

Sulastri, S. 2019. Dasar Pemuliaan Ternak. AURA, CV. Anugrah Utama Raharja.

Suyadi, F. P., \& S. Wahyuningsih. 2017. Performan Reproduksi Pada Persilangan Kambing Boer dan Peranakan Etawah (PE). Jurnal Ilmu-Ilmu Peternakan. 23(1):11-17.
Syahputra, F., \& I. Harris. 2013. Sapih Kambing Peranakan Etawah Di Kecamatan Metro Selatan Kota Metro. Jurnal Ilmiah Peternakan Terpadu. 1(3):1-4. doi:http://dx.doi.org/10.23960/jipt.v1i3.p\%25p.

Warwick, E., J. Astuti, \& W. Hardjosubroto. 1995. Pemuliaan Ternak. Yogyakarta: Gajah Mada University Press. 